
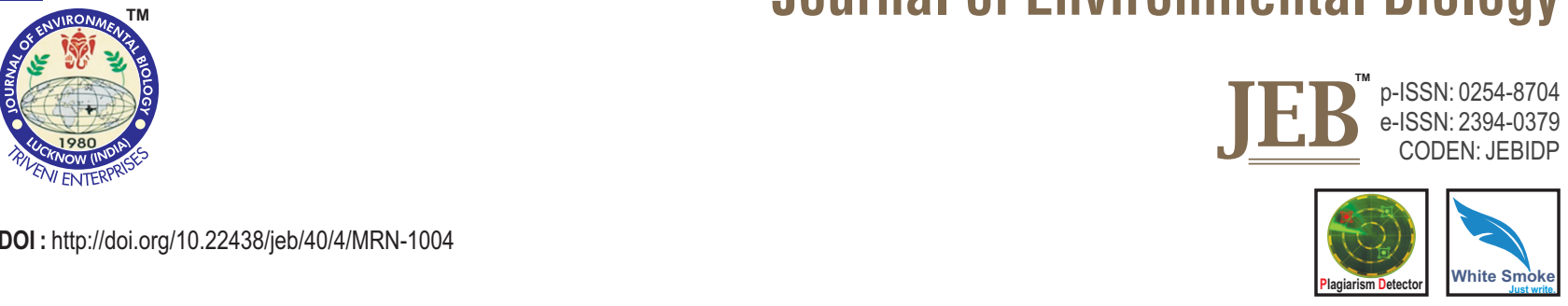

\title{
Temporal changes in behavioural responses and serum metabolites of Cirrhinus mrigala exposed to acute hypoxia
}

\begin{tabular}{llll}
\hline Paper received: 14.09 .2018 & Revised received: 01.12.2018 & Re-revised received: 12.02.2019 & Accepted: 13.02 .2019 \\
\hline
\end{tabular}

\begin{abstract}
Authors Info
T. Varghese $e^{1 *}$, P. Mishal',

G. Gupta', M. Kumar',

A.K. Pal' and S. Dasgupta'

'ICAR-Central Institute of

Fisheries Education,

Mumbai-400 061, India

${ }^{2}$ ICAR-Central Inland Fisheries

Research Institute,

Kolkata-700 120, India

*Corresponding Author Email :

4tincy@gmail.com
\end{abstract}

\section{Edited by \\ Dr. Karan Kumar K. Ramteke}

Reviewed by

Dr. E.M. Hallerman

Dr. K.S. Pillai

\section{Abstract}

Aim : The present study was conducted to determine the tolerance to reduced oxygen level (hypoxia) and the behavioural and biochemical responses of mrigal, Cirrhinus mrigala to environmental hypoxia.

Methodology : Cirrhinus mrigala were subjected to $L_{50}$ test for $96 \mathrm{hr}$ and the mortality were recorded. In a second experiment, the fishes were subjected to a stressful, but safe limit of hypoxia $\left(0.5 \pm 0.04 \mathrm{mgl}^{-1}\right)$ and the behavioral responses and serum metabolites (glucose, lactate, total lipids, free amino acids and ammonia) were evaluated for $96 \mathrm{hrs}$.

Results : A median lethal concentration ( $\mathrm{LC}_{50}, 96 \mathrm{hr}$ ) value of $0.25 \mathrm{mg} \mathrm{l}^{-1}$ dissolved oxygen) was estimated for mrigal. The upper safe limit was $0.49 \mathrm{mg} \mathrm{l}^{-1} \mathrm{DO}$ and the lower lethal limit was $0.19 \mathrm{mg} \mathrm{l}^{-1} \mathrm{DO}$. Gill ventilation frequency increased under severe hypoxic conditions and decreased with exposure time. The serum level of glucose, lactate and total lipids increased significantly $(P<0.05)$ within $24 \mathrm{hr}$ of exposure to hypoxic conditions. Free amino acids and ammonia contents were not altered by a four day exposure to hypoxia.

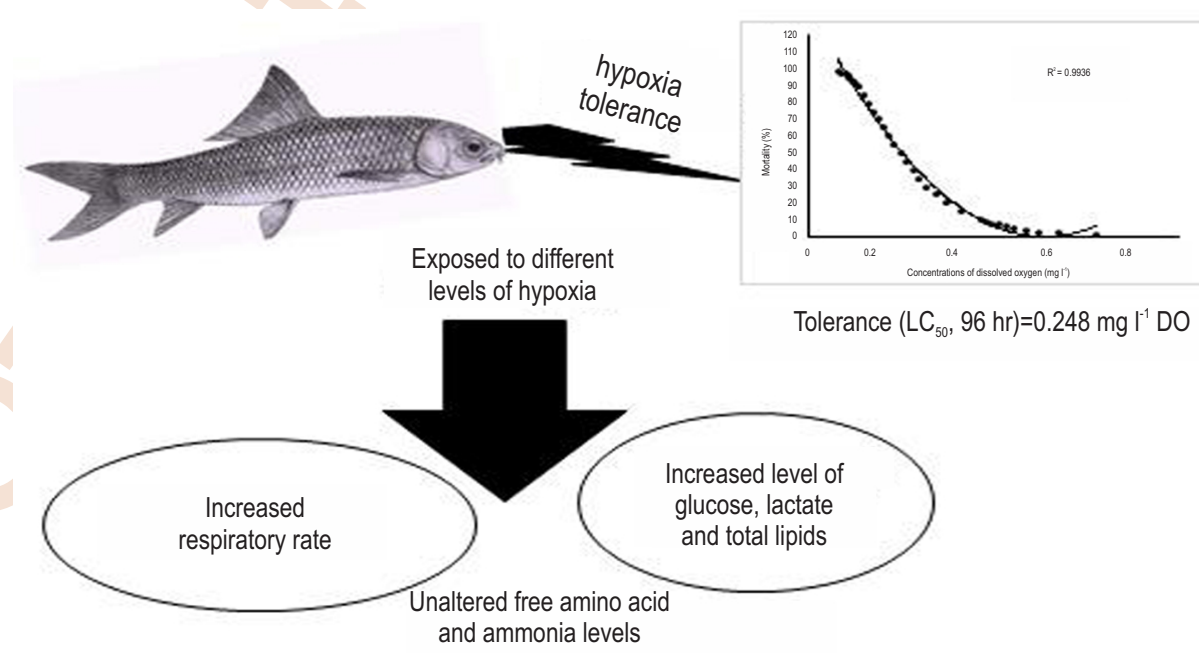

Interpretation : The present study explains the basic metabolic and behavioural mechanism behind the hypoxia tolerance of Indian Major Carp, mrigal assisted by alterations in gill ventilation and metabolic responses.

Key words: Behavioural responses, Cirhinus mrigala, Gill ventilation, Hypoxia, Metabolites

How to cite : Varghese, T., P. Mishal, G. Gupta, M. Kumar, A.K. Pal and S. Dasgupta: Temporal changes in behavioural responses and serum metabolites of Cirrhinus mrigala exposed to acute hypoxia. J. Environ. Biol., 40,641-647 (2019). 


\section{Introduction}

Climate change is a major challenge faced by natural aquatic ecosystems and aquaculture production systems. Hypoxia is one of the major stressor associated with normal summer conditions and changing climatic conditions in the aquatic environment which is detrimental to biotic communities (Diaz and Breitburg, 2009). Oxygen deprivation (hypoxia) in natural waters as well as culture systems can cause episodes of mass mortality of aquatic organisms (Diaz and Rosenberg, 2008; Boero et al., 2016). Hypoxic or often anoxic conditions are experienced in water due to high stocking density, feed wastage, elevated temperatures, cloudy days and eutrophication (Varghese et al., 2018). Additionally, freshwater fishes like Crucian carp (Carassius carassius) inhabit small ponds that can turn severely hypoxic and devoid of dissolved oxygen in winters due to ice formation, preventing exchange of gases at water surface. Many fishes develop different adaptive mechanisms specific to different species depending upon their evolutionary lineage and habitat (Burnett et al., 2001). Deep-sea fishes and bottom-dwelling fishes are generally more tolerant to hypoxia as they thrive in oxygen deficient environments (Friedman et al., 2012).

In response to hypoxia, fish species employ behavioural responses to facilitate $\mathrm{O}_{2}$ uptake and survival (Chapman and McKenzie, 2009). The behavioural response of fishes during hypoxic conditions aid in their survival and sustenance during stress (Smale and Rabeni, 1995). Lack of oxygen can induce both acute and chronic stress responses in fishes (Burnett et al., 2001). In intertidal fishes, the two most common behavioural responses to hypoxic condition in the watercolumn are aquatic surface respiration (ASR) and aerial emergence (Watters and Cech, 2003), which provide more access to $\mathrm{O}_{2}$-rich environments. Fishes exposed to hypoxia improve the efficiency of oxygen supply to the tissues by increasing the rate of respiration and oxygen extraction capacity of gills. Fishes decrease the heart rate and increase the stroke volume, which will increase oxygen diffusion through gills (Farrel et al., 2009). The classic adaptations of metabolism observed in fishes under hypoxic conditions will enable them to supply oxygen to vital organs include reduction in metabolic energy demand, activation of anaerobic energy production and expression of protective proteins during stress (Dunn and Hochachka, 1986; Hochachka and Somero, 2002; Tian et al., 2017).

The ability to adapt to hypoxia vary from species to species and many species of fish can survive severe hypoxic conditions that would be lethal to other species. Identifying hypoxia-tolerant fish species and evaluating their extent of tolerance is critical in the context of changing global climate. This will aid in cataloguing the candidate species for stocking in inland water bodies for enhancement and aquaculture under challenging climatic conditions. It is imperative to study the temporal changes in the behavioural responses and metabolic alterations that enable the tolerant species to survive under extreme conditions. The bottom dwelling carp, mrigal (Cirrhinus mrigala) is supposed to be a tolerant species because of its bottom dwelling nature, however, as of now, only few studies have been undertaken to estimate its hypoxia tolerance capacity (Varghese et al., 2017). Further, the temporal changes in metabolism and behaviour that may explain the mechanism of tolerance need to be investigated. Thus, the present study was undertaken to establish the $\mathrm{LC}_{50}$ values for hypoxia tolerance and behavioural as well as metabolic changes in fingerlings of bottom dwelling carp, Cirrhinus mrigala during acute hypoxic conditions.

\section{Materials and Methods}

Experimental fish: Fingerlings of bottom dwelling carp, Cirrhinus mrigala with an average weight of $7 \pm 0.8 \mathrm{~g}$ were used for the experiments. The fishes were procured from Arey fishfarm, Maharashtra, India and transported in a 500 I container with sufficient aeration to the wet laboratory at Central Institute of Fisheries Education (CIFE), Mumbai. The fishes were carefully transferred to another circular tank $(1000 \mathrm{l})$ and were left undisturbed overnight. The fishes were given a mild salt treatment $(2.0 \%)$ for 2 min next day and acclimatized under aerated conditions $\left(6.5 \pm 0.51 \mathrm{mg} \mathrm{l}^{-1} \mathrm{DO}\right)$. Fishes were fed with a formulated diet $(30 \%$ crude protein and $6 \%$ lipid) for a period of 15 days.

Estimation of median tolerance limit $\left(\mathrm{LC}_{50}\right)$ : The hypoxia tolerance of mrigal was estimated by sing an $L_{50}$ test. Acute toxicity studies were conducted to determine the $96 \mathrm{hr} \mathrm{LC}_{50}$ value under hypoxia following the procedure given in standard methods (APHA 2012). To conduct $L_{50}$ test, a series of six different dissolved oxygen levels were selected with oxygen tensions which produced 0 and 100 per cent mortality fixed as the lowest and highest, respectively. Two hundred fishes were exposed to six different oxygen tensions, $6.5 \pm 0.51,2.0 \pm 0.43,1.5 \pm 0.40$, $1.0 \pm 0.02,0.5 \pm 0.04,0.2 \pm 0.04 \mathrm{mg} \mathrm{l}^{-1}$. Each oxygen level was created and maintained in four tanks, each with ten fishes exposed to defined concentration. All the tanks were first maintained under full aeration, and subsequently a part of aeration was substituted with bubbling of nitrogen, and the dissolved oxygen decreased in a constant, exponential fashion.

The dissolved oxygen levels were adjusted to the required level in each aquarium. Approximately the oxygen levels were decreased $10 \%$ every $40 \mathrm{~min}$, until mortality occurred at 0.2 $\mathrm{mg} \mathrm{l}^{-1}$ dissolved oxygen. The stopping of opercular beating was considered as the criterion to determine death. From the data obtained, median lethal concentration was calculated by Probit Analysis method (Finney, 1947). The experiment was conducted in aquaria of $30 \mathrm{I}$ capacity. The fishes were transferred and left for $48 \mathrm{hr}$ to acclimatize in the aquarium for all the hypoxia experiments. During acclimatization, water was replaced with aerated fresh water and aeration was provided without creating any stress for the fish. The temperature and dissolved oxygen levels were measured every one hour using Multi $240 \mathrm{i}$ instrument (Germany). Temperature was maintained at $26 \pm 1.3^{\circ} \mathrm{C}$. Fish that died during initial exposure due to the pressure difference were removed and moribund ones were removed from the hypoxic 
aquarium and transferred to a well-oxygenated tank. The fish behaviour was recorded in terms of feeding, gill ventilation frequency and surfacing activity, and the results are depicted in Table 1. Surfacing activity was measured as the number of times the fish swims to the surface. Gill ventilation was measured by video recording and counting the number of opercular beats per minute. The feed was offered one time in $24 \mathrm{hr}$ to observe any feeding response. The observations were recorded continuously every

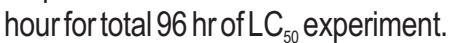

Exposure to acute hypoxic level for 96 hours : A hypoxia level of $0.5 \pm 0.04 \mathrm{mg} \mathrm{l}^{-1} \mathrm{DO}$ was selected for the next experiment based on the upper safe limit of $L_{50}\left(0.49 \mathrm{mg} \mathrm{l}^{-1} \mathrm{DO}\right)$ from ProbitAnalysis (the lowest DO level at which no mortality was noted Fig. 1) The experiment was conducted for $96 \mathrm{hr}$, with one day sampling interval $(0,24,48,72$ and $96 \mathrm{hr})$. No mortality was observed during this period. Fish were not fed during the course of the experiment. The hypoxia level was maintained at $0.5 \pm 0.04 \mathrm{mg} \mathrm{l}^{-1}$ in the same manner as in the $\mathrm{LC}_{50}$ experiment. A total of 150 fish were distributed to 15 experimental units, with 3 replicates for each time interval and having 10 fishes in each aquarium.

Recording of gill ventilation frequency: Gill ventilation frequencies of individual fish were determined with the help of video recording and counting for $30 \mathrm{~min}$ at $6 \mathrm{hr}$ interval. The tanks were kept undisturbed to measure their self-motivated activity as a response to hypoxia.

Estimation of serum metabolites : Periodic sampling was done at $0 \mathrm{hr}, 24 \mathrm{hr}, 48 \mathrm{hr}, 72 \mathrm{hr}$ and $96 \mathrm{hr}$ for estimating serum metabolite concentrations. One fish from each replicate $(n=4)$ was collected and anaesthetised with clove oil $\left(50 \mu \mathrm{I}^{-1}\right)$. Approximately, $150-200 \mu$ l blood was collected from caudal vein of each fish. Serum was separated after incubating $2 \mathrm{hr}$ at room temperature and followed by a centrifugation at $7000 \mathrm{Xg}$ for $5 \mathrm{~min}$. Serum samples were stored at $-20^{\circ} \mathrm{C}$ until further analysis. Blood glucose was estimated by the colorimetric method of Nelson (1944) with slight modifications. Serum lactate levels were measured by the method of Barker and Summerson (1941). Serum and tissue total free amino acids were estimated by Ninhydrin method (Yemm and Cocking, 1955). The level of ammonia in blood samples was estimated by phenol hypochlorite method (Solarzano, 1969). Total lipid in plasma was estimated with Labkit total lipid assay kit (Catalog. No. 30345) following the method of Zollner et al. (1969).

Statistical analysis : All data such as weight of the fish, DO levels and analytical results are expressed as mean $\pm S E$. The median lethal concentration $\left(\mathrm{LC}_{50}\right)$ was analysed by Probit Regression. Temporal changes in behavioural and metabolic responses were analysed by one way ANOVA and post hoc tests were conducted with Duncan's Multiple Range Test at 5\% probability level. All the data were analysed with software SPSS ver. 22.0.

\section{Results and Discussion}

The $\mathrm{LC}_{50}$ values of hypoxia at $96 \mathrm{hr}$ was $0.25 \mathrm{mg} \mathrm{l}^{-1} \mathrm{DO}$ (Fig. 1). The upper safe limit was estimated as $0.49 \mathrm{mg} \mathrm{l}^{-1} \mathrm{DO}$ and the lower lethal limit was $0.19 \mathrm{mg} \mathrm{I}^{-1} \mathrm{DO}$. The regression equation of probit model was $y=339.1 x 2-433.23 x+138.24$ (y-mortality (\%), $x-D O)$. The present study quantified tolerance to hypoxia for

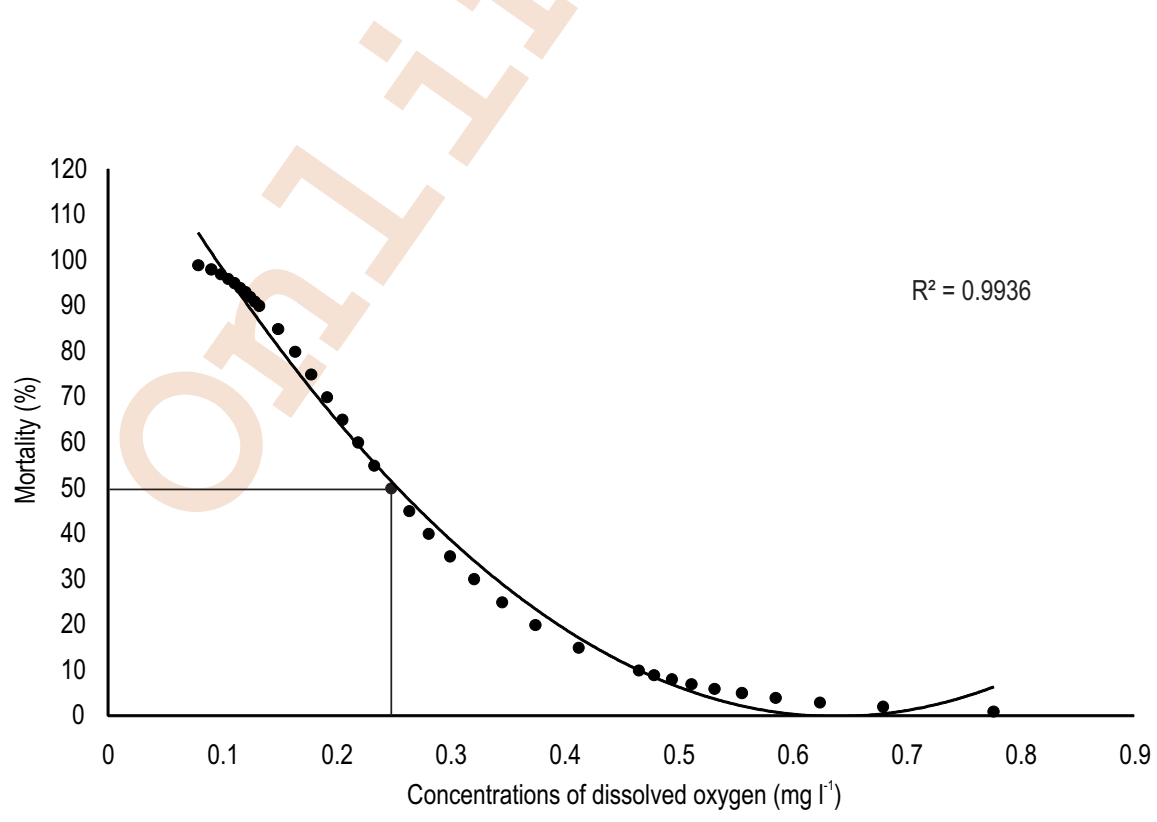

Fig. 1: Percentage mortality of mrigal exposed to different levels of hypoxia for period of $96 \mathrm{hr}$. The $\mathrm{LC}_{50}$ value for $96 \mathrm{hr}$ was $0.248 \mathrm{mg} \mathrm{l}^{-1}$. The upper safe limit was $0.49 \mathrm{mg} \mathrm{l}^{-1}$ and lower lethal limit was $0.19 \mathrm{mg} \mathrm{l}^{-1}$. The regression equation of Probit Model was $\mathrm{y}=339.1 \mathrm{x} 2-433.23 \mathrm{x}+138.24$. Data are expressed as mean \pm S.E. 


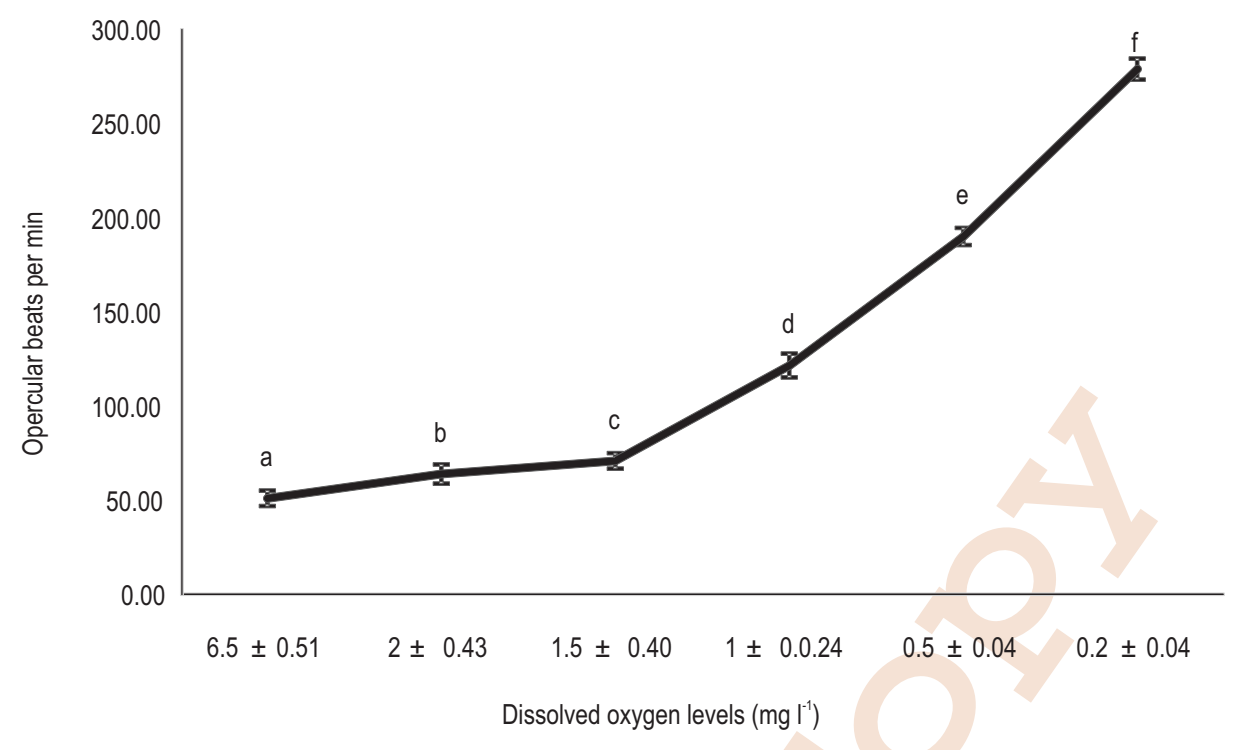

Fig. 2 : Gill ventilation frequencies (Opercular beats per minute) of mrigal exposed to different levels of dissolved oxygen. Different superscripts on the line graph signify statistical differences $(P<0.05)$ among the mean values of dissolved oxygen levels. Data are expressed as mean $\pm S$. E. The regression equation is as follows $y=11.632 x 2-38.786 x+84.462, R^{2}=0.9856$, where $y=$ opercular beats per minute, $x=$ dissolved oxygen

mrigal and monitored temporal changes in behaviour and metabolism during hypoxia. The level of hypoxia tolerance indicates that mrigal is very tolerant to hypoxia, however, they were not tolerant to anoxia. This extreme tolerance was achieved by both behavioural and physiological mechanisms. There are other cyprinids, goldfish and crucian carp, which exhibit high degree of tolerance to hypoxia (Bickler and Buck, 2007). Hypoxia tolerance in terms of Pcrit in another cyprinid, zebra fish was 20 $\mathrm{mm} \mathrm{Hg}$ (Barrionuevo and Burggren, 1999; Barrionuevo et al., 2010). Robertson et al. (2014) showed a considerably higher value that varied between male and female zebrafish.

Results from the first experiment showed that ventilation frequency increased with decreasing oxygen tensions (Fig.2). Gill ventilation frequencies (opercular beats per min, bpm) of the experimental fishes exposed to different levels of dissolved oxygen is represented in Fig. 2. The calculated linear regression equation for the data was $y=44.811 x-27.483$, where $y=$ gill ventilation rate, $x$ is the dissolved oxygen levels. Gill ventilation rates at all the lower levels of oxygen tensions were significantly higher $(P<0.05)$ than those values observed during normoxia $\left(6.5 \pm 0.51 \mathrm{mg} \mathrm{l}^{-1} \mathrm{DO}\right)$. Also, gill ventilation frequencies at all the levels were significantly different from each other $(P<0.05)$ (Fig.2) and increased significantly $(P<0.05)$ towards the lower levels. The ventilation frequency increased from $51 \pm 1.0 \mathrm{bpm}$ at normoxia ( $\left.6.5 \pm 0.5 \pm 0.04 \mathrm{mg} \mathrm{l}^{-1} \mathrm{DO}\right)$ to $278 \pm 5.5 \mathrm{bpm}$ at lowest exposed oxygen tension $\left(0.2 \pm 0.04 \mathrm{mg} \mathrm{l}^{-1} \mathrm{DO}\right)$ during the experiment. The calculated correlation coefficient for linear regression of oxygen tension and gill ventilation rate was 0.86 This study demonstrate some of the behavioural responses of fish in response to acute hypoxic conditions. The most evident behavioural response to hypoxia is hyperventilation. An increase in ventilation frequency is observed in zebra fish with decrease in oxygen tensions (Vulesevic and Perry, 2006). Increased gill ventilation is a common strategy during hypoxic survival which aid in extracting more oxygen than those obtained with normal ventilation frequencies. Hypoxia causes an enhanced ventilation frequency upto 1.6 fold from 60 to 100 and from 27 to 45 beats $\mathrm{min}^{-1}$, respectively, in rainbow trout, Oncorynchus mykiss and sea bass, Dicentrarchus labrax (Thomas and Hughes, 1982).

In contrast, the second experiment revealed that the gill ventilation frequency at $0.5 \pm 0.04 \mathrm{mg} \mathrm{l}^{-1}$ with respect to exposure time (hr) decreased significantly $(\mathrm{P}<0.05)$ upto $72 \mathrm{hr}$ from a level of $278 \pm 2.4 \mathrm{bpm}$ to $120 \pm 6.0 \mathrm{bpm}$ and remained at same level $(P>0.05)$ on $96 \mathrm{hr}$ ( Fig. 3). The gill ventilation rates at $24 \mathrm{hr}, 48 \mathrm{hr}$ and $72 \mathrm{hr}$ were significantly $(\mathrm{P}<0.05)$ different among themselves. However, the gill ventilation rate stabilises after $72 \mathrm{hr}$, although it continues at a higher rate than at normoxic conditions. These results indicate that with longer duration of exposure, fish survive at lower gill ventilation rates, this may be due to the suppression of metabolism and oxygen demand, occurring due to short-term physiological adaptations in fishes (Chapman and McKenzie, 2009; Varghese et al., 2018). Concomitant with increased gill ventilation rates, additional alterations in the behavioural responses offish (Table 1) were also observed. As dissolved oxygen level decreased, the fish started to beat their opercula at a higher rate, which was found to increase towards the lower dissolved oxygen levels. The study further showed that threshold of feeding response during hypoxia was $1.0 \pm 0.1 \mathrm{mg} \mathrm{l}^{-1}$, 
below which the fish would not accept feed, because the animals cannot afford the energy demand associated with feed intake and metabolism, as there is deficiency of oxygen required for metabolism of nutrients.

The swimming activity of fish reduced with decreasing dissolved oxygen levels. The animals remained still at the bottom without any kind of swimming movement below a dissolved oxygen level of $0.5 \pm 0.04 \mathrm{mg} \mathrm{l}^{-1}$ (Table1). The effect of hypoxia on swimming activity varied among different species such as rainbow trout and seabass (Thomas and Hughes, 1982). Lower swimming activity levels at oxygen tensions below the critical $P_{02}$ $\left(P_{\text {citi }}\right)$, may be regarded as a strategy to conserve energy in an environment of potentially limited $\mathrm{O}_{2}$ availability; however, the intense agitating behaviour of fish in severe hypoxia below Pcrit is regarded as an acute escape or avoidance response (Van Raaji et al., 1996). Increased swimming activity under severe hypoxia may increase gas exchange at the surface (Chapman and Mckenzie, 2009). Previous studies have shown that zebrafish increased swimming activity as $\mathrm{PO}_{2}$ continued to decline. At a dissolved oxygen level below $0.5 \pm 0.04 \mathrm{mg} \mathrm{l}^{-1}$, fish frequently displayed surfacing activity or remained hanging near the surface (Table 1). Thus, surfacing rate increased with severity of hypoxic conditions in mrigal, which was also observed in zebrafish that exhibited aquatic surface respiration with decrease in oxygen tensions and it did not remain at the surface of the chamber, instead moved up and down to improve gill ventilation (Abdallah, 2015). Another study (David et al., 2015) also revealed that the tissue level hypoxia induced by sodium cyanide in $L$. rohita resulted in the disruption of normal behaviour of fish. Significant alterations in metabolic pathways were also observed during hypoxia. The glucose and lactate levels were estimated at different time intervals (Table 2) to measure the extent of anaerobic metabolism. Serum glucose levels in the fish exposed to hypoxia increased significantly $(P<0.05)$, immediately within 24 $\mathrm{hr}\left(140.3 \pm 3.1 \mathrm{mg} \mathrm{dl}^{-1}\right)$ and decreased there after on $48 \mathrm{hr}$ $\left(131.3 \pm 2.1 \mathrm{mg} \mathrm{dl}^{-1}\right)$. The changes were significant $(P<0.05)$ during the first $24 \mathrm{hr}$ after exposure to hypoxia and declined to lower levels from $48 \mathrm{hr}$ onwards. However, the values remained at same levels for the rest of experimental period, and were higher than the normal glucose levels at $0 \mathrm{hr}\left(85.1 \pm 2.9 \mathrm{mg} \mathrm{dl}^{-1}\right)$. The present study shows that serum lactate concentrations in mrigal increased $(P<0.05)$ and reached maximum $48 \mathrm{hr}\left(63.61 \pm 2.71 \mathrm{mg} \mathrm{m}^{-1}\right)$ with respect to $0 \mathrm{hr}$ $\left(18.71 \pm 1.97 \mathrm{mg} \mathrm{ml}^{-1}\right)$ immediately after exposure to hypoxia.

The difference between the $48 \mathrm{hr}, 72 \mathrm{hr}$ and $96 \mathrm{hr}$ were non-significant $(P>0.05)$. Thus, the fish maintained serum lactate at $48 \mathrm{hr}$ levels throughout the remaining $96 \mathrm{hr}$ of hypoxic exposure, indicating higher anaerobic metabolism while surviving lower oxygen tensions. Glucose is the most readily available metabolic substrate during hypoxic conditions and is used for producing energy through glycolytic pathway (Martinez et al., 2017). There was a shift in metabolic pathway towards anaerobic glycolytic energy production as it is rapid and yields ATP without oxygen demand (Zheng, 2012). The metabolism of aquatic animals such as jellyfish are influenced by abiotic stress factors (Boero et al., 2016). Carps employ a metabolic adaptation wherein a further reduction of lactate to ethanol is carried out under anaerobic conditions (Van Waarde, 1991). Furthermore, higher blood and tissue lactate concentrations are also reasonably a good indicator of anaerobic metabolism (Tota et al., 2011). Similar results were observed in hypoxia-exposed rainbow

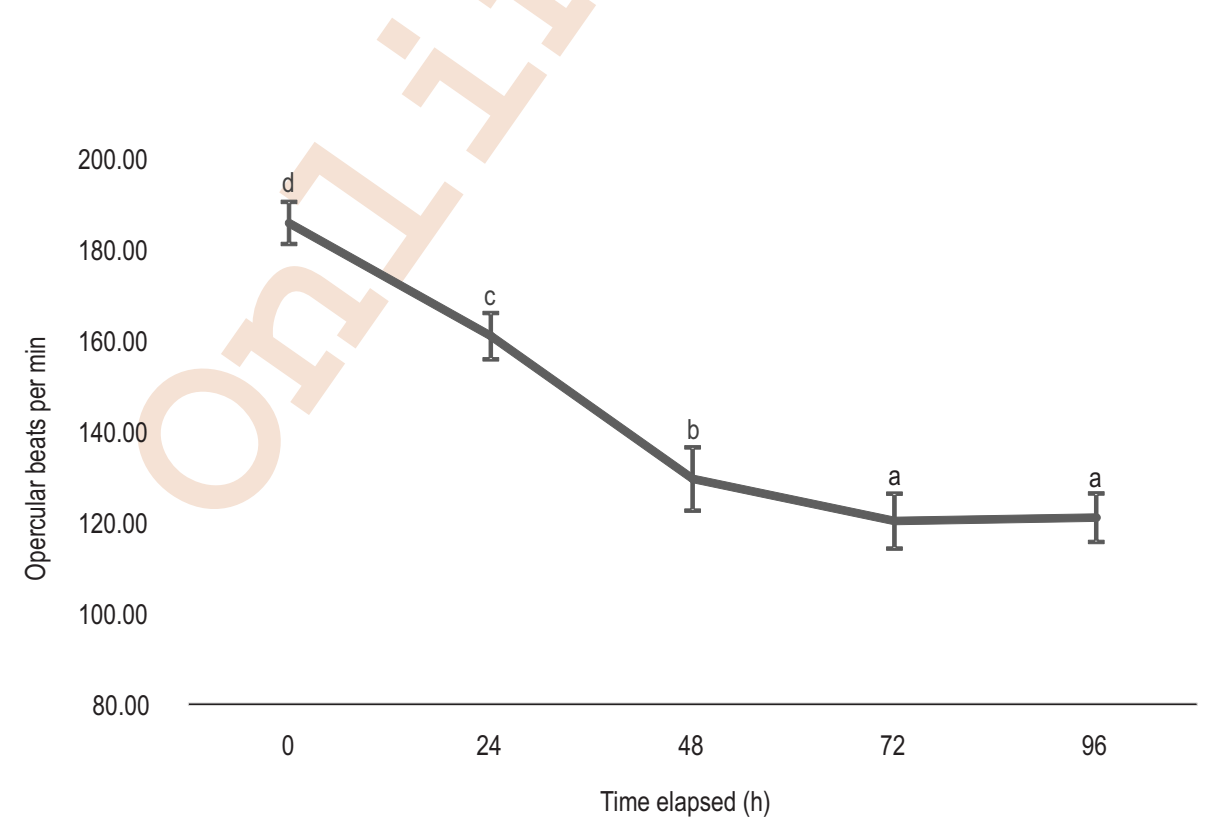

Fig. 3 : Gill ventilation frequencies of mrigal at different times at $0.5+0.04 \mathrm{mg} \mathrm{l}^{-1}$ dissolved oxygen. Different superscripts in the line graph signify statistical differences $(P<0.05)$ among the mean values of timepoints. Data are expressed as mean $\pm S . E$. 
Table1: Overall behavioural changes of mrigal at $96 \mathrm{hr}$ of exposure to different dissolved oxygen $\left(\mathrm{mg} \mathrm{l}^{-1}\right)$ levels

\begin{tabular}{lllllll}
\hline Changes in behaviour & $6.5 \pm 0.51$ & $2.0 \pm 0.43$ & $1.5 \pm 0.40$ & $1.0 \pm 0.02$ & $0.5 \pm 0.04$ & $0.2 \pm 0.04$ \\
\hline GVF $^{1}$ & Normal & Normal & Hyper & Hyper & Hyper & Hyper \\
& ventilation & ventilation & ventilation & ventilation & ventilation & ventilation \\
Surfacing & Nil & Nil & Nil & Nil & Very often & Stays at surface \\
Swimming activity & Active & Active & Active & Active & Inactive & Inactive \\
Feeding & Accept feed & Accept feed & Accept feed & Accept feed & No feeding & No feeding \\
\hline
\end{tabular}

${ }^{1}$ Gill Ventillation Frequency. Data is expressed qualitatively based on continuous observations of all the exprerimental groups

trout where acute exposure to hypoxia increased lactate levels in blood from normoxic values of $\sim 1$ to $615 \mathrm{mM}$, and lactate levels in tissues from 1 to $11 \mu \mathrm{mol} \mathrm{g}$ tissue (Omlin and Weber, 2010). Another striking observation is that hypoxia not only increases lactate production but also strongly stimulate lactate disposal (Diaz and Breitburg, 2009). Thus, anaerobic metabolic capacity of fish was evident from the temporal changes in the parameters such as high serum glucose and lactate levels observed even after 96 hr exposure to hypoxia.

High serum lipid levels were observed in the experimental groups at $72 \mathrm{hr}\left(1.73 \pm 0.14 \mathrm{gdl}^{-1}\right)$ compared to those at $0 \mathrm{hr}, 24 \mathrm{hr}$ and $48 \mathrm{hr}$ and maintained at those levels afterwards (Table 2) during hypoxic exposure. The lipid levels did not vary significantly ( $P>0.05)$ among first three observations (0 hr, $24 \mathrm{hr}$ and $48 \mathrm{hr}$ ). Serum lipid levels increased after $72 \mathrm{hr}$ of hypoxia, indicating that lipid mobilisation occurs later than use of carbohydrate substrates. Meanwhile, the serum ammonia contents and free amino acids remained statistically similar $(P>0.05)$ for the entire experimental period. The unaltered free amino acids and ammonia levels during exposure to hypoxia showed that amino acid mobilisation from the tissues was meagre compared to glucose and lipid utilisation. It may be beacuse a period of $96 \mathrm{hr}$ of hypoxia exposure is not sufficient to induce body protein degradation in this tolerant species. Siques et al. (2014) reported that triglycerides and LDL-cholesterol increased during chronic hyperbaric hypoxia in Wistar rats which was due to mobilization of lipids during hypoxic stress. Lipid peroxidation is another phenomenon observed during hypoxia
(Varghese et al., 2017). During hypoxia, although there is no supply of food nitrogen or protein degradation, ammonia can be produced through deamination of AMP (adenosine monophosphate) in the skeletal muscle during hypoxia (Ip and Chen, 2010). These results are in contrast with the findings of Medale et al.(1987), who found a decrease in plasma free amino acids in rainbow trout when subjected to long term hypoxia. These results suggest an adaption for long-term hypoxia where anabolism is negatively regulated in order to limit energy requirement (Medale et al., 1987) whereas the present study only deals with short-term acute exposure to hypoxia. The study implies that mrigal utilise carbohydrate substrates during exposure to hypoxia and that lipids are the second preferred substrate for metabolic energy needs, which is a different utilisation pattern than carnivorous species like salmonids.

It is apparent that mrigal exhibits high level of hypoxia tolerance, and altered metabolic and behavioural responses under hypoxia. In addition, the fish also survived without feed intake, likely to achieve a state of metabolic suppression and lower oxygen demand. The metabolic alterations indicated that protein degradation was minimal and that energy metabolism was mostly dependent on carbohydrate and lipid as metabolic fuels. These adaptations enable them to survive short hypoxic episodes in natural waters due to warm or cloudy weather conditions. Overall, the study indicate that mrigal is a hypoxia tolerant species, which adjust both behaviour and metabolism in order to survive in low oxygen tensions.

Table 2 : Alteration in serum metabolites during exposure to hypoxia

\begin{tabular}{llllll}
\hline $\begin{array}{l}\text { Time period of } \\
\text { exposure }(\mathrm{hr})\end{array}$ & $\begin{array}{l}\text { Glucose } \\
\left(\mathrm{mg} \mathrm{dl}^{-1}\right)\end{array}$ & $\begin{array}{l}\text { Lactate } \\
\left(\mathrm{mg} \mathrm{ml}^{-1}\right)\end{array}$ & $\begin{array}{l}\text { Total lipids } \\
\left(\mathbf{g ~ d l}^{-1}\right)\end{array}$ & $\begin{array}{l}\text { Free amino } \\
\text { acid }\left(\mathrm{mg} \mathrm{ml}^{-1}\right)\end{array}$ & $\begin{array}{l}\text { Ammonia } \\
\left(\mathrm{mg} \mathrm{dl}^{-1}\right)\end{array}$ \\
\hline 0 & $85.04^{\mathrm{a}} \pm 2.89$ & $18.71^{\mathrm{a}} \pm 1.97$ & $1.18^{\mathrm{a}} \pm 0.03$ & $2.43 \pm 0.17$ & $14.60 \pm 0.84$ \\
24 & $140.33^{\mathrm{c}} \pm 3.18$ & $40.32^{\mathrm{b}} \pm 0.54$ & $1.17^{\mathrm{a}} \pm 0.03$ & $2.70 \pm 0.28$ & $15.67 \pm 0.26$ \\
48 & $131.38^{\mathrm{b}} \pm 2.03$ & $63.61^{\mathrm{c}} \pm 2.71$ & $1.31^{\mathrm{a}} \pm 0.11$ & $2.92 \pm 0.14$ & $14.00 \pm 0.87$ \\
72 & $133.67^{\mathrm{b}} \pm 5.78$ & $68.63^{\mathrm{c}} \pm 4.13$ & $1.73^{\mathrm{b}} \pm 0.14$ & $2.85 \pm 0.18$ & $14.60 \pm 0.46$ \\
96 & $135.33^{\mathrm{b}} \pm 6.64$ & $59.40^{\mathrm{c}} \pm 3.87$ & $1.84^{\mathrm{b}} \pm 0.09$ & $2.89 \pm 0.02$ & $14.29 \pm 0.19$ \\
P value & 0.001 & 0.001 & 0.001 & 0.339 & 0.412 \\
\hline
\end{tabular}

Data are mean six replicates \pm S.E. Different superscripts in same column signify statistical differences $(P<0.05)$ 


\section{Acknowledgments}

This work is a part of Ph.D thesis of first author. The authors acknowledge the financial support from Indian Council of Agricultural Research (ICAR), New Delhi. The first author is thankful to the Director, ICAR-Central Institute of Fisheries Education, Mumbai for the support and facilities provided to conduct the study.

\section{References}

Abdallah, S. J., B. S. Thomas and M. G. Jonz: Aquatic surface respiration and swimming behaviour in adult and developing zebrafish exposed to hypoxia. J. Exp. Biol., 218, 1777-1786 (2015).

APHA: Standard methods for the examination of water and wastewater. $22^{\text {nd }}$ Edn., APHA, AWWA, WEF, Washington DC, USA(2012).

Barker, S. B. and W. H. Summerson: Colorimetric determination of lactic acid in biological material. J. Biol. Chem., 138, 535-547 (1941).

Barrionuevo, W. R. and W. W. Burggren: $\mathrm{O}_{2}$ consumption and heart rate in developing zebrafish (Danio rerio): Influence of temperature and ambient O 2. Ameri. J. Physiol., 276, 505-513 (1999).

Barrionuevo, W. R., M. N. Fernande and O. Rocha: Aerobic and anaerobic metabolism for the zebrafish, Danio rerio, reared under normoxic and hypoxic conditions and exposed to acute hypoxia during development. Brazil. J. Biol., 70, 425-434 (2010).

Bickler, P. E. and L. T. Buck: Hypoxia tolerance in reptiles, amphibians and fishes: Life with variable oxygen availability. Ann. Rev. Physiol., 69, 145-70 (2007).

Boero, F., L. Brotz, M.J. Gibbons, S. Piraino and S. Zampardi: Ocean warming 3.10 impacts and effects of on jellyfish. IUCN, Gland 213-237 (2016)

Burnett, E. L. and W. B. Stickle: Physiological responses to hypoxia. In: Coastal hypoxia: Consequences for living resources and ecosystems (Eds.: N.N. Rabalais and R.E. Turner) Washington, USA: American Geophysical Union., pp. 101-114 (2001).

Chapman, L. J. and D. J. McKenzie: Behavioural responses and ecological consequences. In: Hypoxia. (Eds.: J.G. Richards, A. P. Farrell and C.J. Brauner) Amsterdam, Netherlands, Elsevier, pp. 25-77 (2009).

David, M., J. Sangeetha and E.R. Harish: Sodium cyanide induced alteration in the whole animal oxygen consumption and behavioural pattern of freshwater fish Labeo rohita. J. Environ. Biol., 36, 405-408 (2015).

Diaz, R.J. and R. Rosenberg: Spreading dead zones and consequences for marine ecosystems. Sciences, 321, 926-929 (2008).

Diaz, R. J. and D. L Breitburg: The hypoxic environment. In: Fish Physiology: Hypoxia (Eds.: A.P. Farrel and C.J. Brauner), Academic Press, London, pp. 1-15(2009).

Dunn, J. F. and P. W. Hochachka: Metabolic responses of the trout (Salmo gairdneri) to acute environmental hypoxia. J. Exp. Biol. 123, 229-242(1986).

Farrell, A. P., E. J. Eliason, E. Sandblom and T. D. Clark: Fish cardiorespiratory physiology in an era of climate change. Canad. J. Zool., 87, 835-851 (2009).

Finney, D. J.: Probit analysis: Astatistical treatment of the sigmoid response curve. Cambridge, UK: Cambridge University Press (1947).

Friedman, J. R., N. E. Condon and J. C. Drazen: Gill surface area and metabolic enzyme activities of demersal fishes associated with the oxygen minimum zone off California. Limnol. Oceano., 57, 1701$1710(2012)$

Hochachka, P.W. and G.N. Somero: Biochemical adaptation, mechanism and processes in physiological evolution. Oxford: Oxford University Press, New York (2002).
Ip, Y.K. and S.F. Chew: Ammonia production, excretion, toxicity and defence in fish:A review. Front. Physio., 1, 134 (2010).

Martinez-Outschoorn, U.E., M. Peiris-Pages, R.G. Pestell, F. Sotgia and M.P. Lisanti: Cancer metabolism: A therapeutic perspective. Nature Rev. Clin. Oncol., 14, 11 (2017).

Medale, F., J. P. Parent and F. Vellas: Responses to prolonged hypoxia by rainbow trout (Salmo gairdneri) I. Free amino acids and proteins in plasma, liver and white muscle. Fish Physiol. Biochem., 3, 183189 (1987).

Nelson, N. A.: Photometric adaptation of the Somogyi method for the determination of glucose. J. Biolog. Chem., 163, 375-380 (1944).

Omlin, T. and J. M. Weber: Hypoxia stimulates lactate disposal in rainbow trout. J. Exp. Biol., 213, 3802-3809 (2010)

Robertson, C. E., P.A. Wright, L. Koblitz and N. J. Bernier: Hypoxiainducible factor-1 mediates adaptive developmental plasticity of hypoxia tolerance in zebrafish, Danio rerio. Proc. R. Soc. B, 281, 20140637 (2014).

Siques, P., J. Brito, N. Naveas, R. Pulido, J. J. De la Cruz, M. Mamani and F. León-Velarde: Plasma and liver lipid profiles in rats exposed to chronic hypobaric hypoxia: Changes in metabolic pathways. High Altitude Medi. Bio., 15, 388-395 (2014).

Smale, M. A. and C. F. Rabeni: Hypoxia and hyperthermia tolerances of headwater stream fishes. Trans. Am. Fish. Soc., 124,698-710 (1995).

Solarzano, L.: Determination of ammonium in natural waters by phenol hypochlorite method. Limnol. Oceano., 14, 799-800 (1969).

Thomas, S. and G. M. Hughes: Effects of hypoxia on blood gas and acid base parameters of sea bass. J. Appl. Physiol., 53,1336-1341 (1982)

Tian, R., M. Losilla, Y. Lu, G. Yang and H. Zakon: Molecular evolution of globin genes in Gymnotiform electric fishes: Relation to hypoxia tolerance. BMC Evol. Biol., 17, 51 (2017).

Tota, B., T. Angelone, D. Mancardi and M. C. Cerra: Hypoxia and anoxia tolerance of vertebrate hearts: An evolutionary perspective. Antioxid. Redox Sign., 14, 851-862 (2011).

Varghese, T., A. K. Pal, N. P. Sahu, P. Mishal and S. Dasgupta: Effects of hypoxia and dietary Vitamin $E$ on growth performance and oxidative status of Cirrhinus mrigala (Ham., 1822). Anim. Biol., 67, 133-148 (2017).

Varghese, T., A. K. Pal, P. Mishal, N. P. Sahu and S. Dasgupta: Physiological and molecular responses of a bottom dwelling carp, Cirrhinus mrigala to short-term environmental hypoxia. Turk. J. Fish. Aquat. Sc., 18, 483-490 (2018).

Van Raaji, M.T.M., G.E.E. J.M. Varden Thillart, G. J. Vianen, D. S. S. Pit, P. H. M., Balm and A. B Steffens: Substrate mobilization and hormonal changes in rainbow trout (Oncorhynchus mykiss, L.) and common carp (Cyprinus carpio L.) during deep hypoxia and subsequent recovery. J. Compar. Physiol. B., 166, 443-452 (1996)

Van Waarde, A.: Alcoholic fermentation in multicellular organisms. Physiol. Zool., 64, 895-920 (1991).

Vulesevic, B. and S. F. Perry: Developmental plasticity of ventilatory control in zebrafish, Danio rerio. Respir. Physiol. Neurobiol., 154, 396-405 (2006).

Watters, J. V. and J. J. Cech: Behavioural responses of mosshead and wooly sculpins to increasing environmental hypoxia. Copeia, 3 , 397-401 (2003).

Yemm, E. W. and E. C. Cocking: The determination of amino acids with ninhydrin. Analyst., 80, 209-213 (1955).

Zheng, J. I. E.: Energy metabolism of cancer: Glycolysis versus oxidative phosphorylation (Review). Oncology Letters, 4, 11511157(2012).

Zollner, N., G. Wolfram, W. Londong and K. Kirsch: Study of plasma lipids in newborn infants and young children. Klin Wochenschr, 44, 380$386(1966)$. 